\title{
Attitudes, experience and expectations of health service users regarding nutritional advice and its source
}

\author{
H. Dewhurst and P. Neild \\ St George's University of London, Cranmer Terrace, Tooting, London, SW17 ORE, UK
}

Nutrition is a key factor in health maintenance and amelioration of certain disease states ${ }^{(1)}$. It is thus important that people are able to access accurate information - especially advice about dietary issues shown to have a beneficial effect on a variety of chronic illnesses ${ }^{(2,3)}$. The aim of the study was to understand how healthcare users access nutritional information, and their views and expectations on who is and who should be best suited to delivering such nutritional information.

This study was based on an online questionnaire, designed in the format of previous studies of a similar nature ${ }^{(4,5,6,7)}$ and advertised to members of various disease-associated charities via email, newsletter or website posting. All results were anonymous and The South West London Research Ethics Committee advised that ethical approval was not necessary.

Two hundred and ten participants completed the questionnaire, showing a diverse range of sources were used to access nutritional information. The Internet and food package labelling being the most commonly used resources, as seen below:

\begin{tabular}{lc}
\hline Source & $\begin{array}{c}\text { Participants listing source as } \\
\text { most commonly used (\%) }\end{array}$ \\
\hline The Internet & 31.2 \\
Information from food & 25.5 \\
packaging & \\
Magazines/newspapers & 9.9 \\
Family & 8.5 \\
GP & 5.7 \\
Nurse & 5.7 \\
Hospital Doctor & 5.0 \\
Friends & 4.3 \\
TV/Radio & 4.3 \\
\hline
\end{tabular}

There was a difference between where men and women accessed the majority of their information $(p<0.05)$, with women most commonly acquiring information from food packaging and men from family and friends. Those surveyed generally judged that junior doctors gave the least satisfactory nutritional advice and, indeed, of the health professionals listed, hospital doctors were felt to be the least approachable as sources of nutritional information. Acquisition of information from the Internet appears to have expanded dramatically compared to previous studies, and information on food packaging is becoming one of the main sources of nutritional information.

This study shows that healthcare users acquire information from a variety of sources and educational campaigns need to acknowledge and exploit this. Respondent's negative experience and perception of some groups of doctors as a source of nutritional information is concerning and possible reasons for this require further exploration.

1. World Health Organisation [homepage online]. [cited 2011 Jan 14]; Available from: URL: http://www.who.int/en/

2. National Institute of Diabetes and Digestive and Kidney Diseases [homepage online]. [cited 2010 Nov 26]; Available from: URL: http://www2.niddk. nih.gov/

3. Brown K \& Phillips T (2010) Clin Dermatol 28, 432-439.

4. Medeiros L, Russell W \& Shipp R (1991) Nut Res 11, 979-988.

5. Hiddink G, Hautvast J, Woerkum C et al. (1997) Am J Clin Nutr 65, 1974-1979.

6. Lappalainen R, Kearney J \& Gibney M (1998) Food Qual Prefer 9, 467-478.

7. McKay D, Houser R, Blumberg J et al. (2006) J Am Diet Assoc 106, 1108-1111. 